Research Article

\title{
A prospective study of level of satisfaction among surgical patients in a tertiary care hospital of central India
}

\author{
Anant Kumar Rakhonde, Amarnath Seth, Neeta Rakhonde, Roshan Chanchlani*
}

Department of Surgery, Chirayu Medical College and Hospital, Bhopal, M.P., India

Received: 28 September 2015

Revised: 03 October 2015

Accepted: 08 October 2015

\section{*Correspondence:}

Chanchlani Roshan,

E-mail: roshanchanchlani@gmail.com

Copyright: ( $)$ the author(s), publisher and licensee Medip Academy. This is an open-access article distributed under the terms of the Creative Commons Attribution Non-Commercial License, which permits unrestricted non-commercial use, distribution, and reproduction in any medium, provided the original work is properly cited.

\begin{abstract}
Background: Patient satisfaction is one objective of care, and along with recovery from illness or amelioration of presenting problem, it is therefore an outcome of care too. The objective of the study was to evaluate the satisfaction level among surgical patients before and after counselling and to studies the relationship of literacy and acceptance for surgery.

Methods: Patients coming to surgical OPD, having definite surgical problem and who needs surgical intervention are taken into consideration. 108 patients were selected on pilot basis. Depending on the common complaints by patient regarding doctor patient relationship and satisfaction of patient after consultation at our institute, a five point questionnaire was prepared with an option to answer as satisfied, partially satisfied and not satisfied with reasons.

Results: In our study total 108 patients coming to surgical OPD were taken. Out of which $66(61.11 \%)$ were males and $42(38.88 \%)$ were females. All of them are above 18 years of age group. The youngest was 18 years and oldest was 66 years of age. Females were found to be more satisfied after patient empowerment and counselling as compared to males. Older patients were found to be more satisfied than younger ones which are comparable with the international studies. In our study, females took much time for empowerment, understanding and counselling but found to be more firm on the decision once taken by them. In our study, overall satisfaction level of patients has increased after counselling and patient empowerment (from $37 \%-63 \%$ ).

Conclusions: Making of a successful surgeon requires apart from extensive knowledge of his subject, he should be able to know the psyche of patients, hearing them and giving them sufficient time will solve most of problems for flourishing his practice, becoming a good ,sensible and famous surgeon and will help to avoid so many unnecessary medico-legal litigations against innocent surgeons.
\end{abstract}

Keywords: Surgical intervention, Patient empowerment, Medico-legal litigations

\section{INTRODUCTION}

Patients' satisfaction is a must while managing any patient. Especially it becomes more important when a patient has to be managed by some surgical intervention. Compliance of any patient is a measure of his or her confidence on the treating physician. No confidence no compliance. Surgery causes stress and strain to patient. Patient satisfaction is one objective of care, and along with recovery from illness or amelioration of presenting problem, it is therefore an outcome of care too. It is also a contributor to outcome, as satisfied patients are more likely to cooperate with treatment. ${ }^{1}$ Satisfaction is the patient's judgement of quality of care. ${ }^{2}$ In addition to these there is a philosophical view that patients should by right have their concerns about care taken into account. The growing importance of consumerism in healthcare is but one element of a broader social movement and it 
would be unrealistic to expect that health services will be allowed to remain undisturbed by changes taking place in the rest of society. ${ }^{3}$ Baker was the first UK researcher to produce reliable and valid scale designed to look specifically at satisfaction with general practitioners services. ${ }^{4}$ Baker introduced , 'the consultation satisfaction questionnaire' and' surgery satisfaction questionnaire. Assessment of patient's satisfaction has been used as a measure of outcome in studies of aspects of general practice such as deputizing, length of consultations and workload. ${ }^{5-7}$ The problem can be solved by patient empowerment, proper listening, attention, time given to the patient and empowering him by latest knowledge by means of counselling. This in turn will develop confidence of patient in his surgeon and will solve so many unnecessary problems. Proper counselling of surgical patients will solve the problem to a greater extent although it is cumbersome, pain taking and time consuming process, but will help to alleviate maximum amount of stress of surgeons in pre-op, intra-op, immediate post-op, and long term complications including medico-legal suits against treating surgeon. Keeping these things in mind a prospective questionnaire based study is undertaken with following aims and objectives.

\section{Aims and objectives}

The objectives of the study were as follows.

1. To study the satisfaction level among surgical patients before and after counselling.

2. To study the relationship of literacy and acceptance for surgery.

3. To get a feedback on our workings.

4. An attempt to study the psychology of surgical patients.

5. To improve physicians and their short comings.

6. To determine an optimal time for surgical counselling.

\section{METHODS}

\section{Inclusion criteria}

Patients coming to surgical OPD, having definite surgical problem and who needs surgical intervention are taken into consideration. Only routine surgery patients are included. Patients of either sex or age 18-65 yrs. were taken. 108 patients were selected on pilot basis.

\section{Exclusion criteria}

Patients requiring emergency surgery.

\section{Methods}

Depending on the common complaints by patient regarding doctor patient relationship and satisfaction of patient after consultation at our institute, a five point questionnaire is prepared with an option to answer as satisfied, partially satisfied and not satisfied with reasons if they want to explain according to their opinion. The study is done in two steps.

Step 1: In OPD after detailed history and physical examination, diagnosis is told to the patient and a questionnaire containing five items were asked.

Step 2: Counselling of patient is done regarding his disease as nature of disease, its etiology, pathology, various modalities of treatment available and probable outcome. Again five item questionnaire is asked and level of satisfaction is noted. Any decrease or increase in satisfaction level is noted and reason is asked to the patient regarding the same and some correlation is tried to establish.

\section{Questionnaire asked}

Q-1: Doctor has heard my problems satisfactorily.

Q-2: Doctor has examined me patiently.

Q-3: You have been satisfactorily told about your disease.

Q-4: Are you satisfied with the diagnosis made.

Q-5: Will you go for surgery.

Results were noted as: Satisfied or yes, partially satisfied or can't say and not satisfied or no, before and after counselling and following observations were made. The results were analysed using SPSS19 and statistical values were evaluated using chi square test, degree of freedom, and p-value.

\section{RESULTS}

In Table 1, there is significant rise in the satisfaction level of patient post counselling and it is found that the patients agreed that doctor has heard them satisfactorily is found to be statistically significant, chi square value $=49.83$, pvalue $=0.001$ and degree of freedom $\mathrm{df}=2$. Post counselling, i.e. after spending extra time with the patient and patient hearing of patients and spending extra time with the patient, listening patients quietly developed positive thought in the patient that the doctor has seen the patient.

In Table 2, There was not significant change in the satisfaction level of patients for examination, chi square value $=3.51, \mathrm{p}$-value $=0.17$ and degree of freedom $\mathrm{df}=$ 2 , so statistically insignificant. After counselling, only 6 $(5.5 \%)$ patient has requested to re-examine them.

In Table 3, There was a significant change in the satisfaction level of patients post counselling regarding explanation about the disease condition to the patient is found to be statistically significant, chi square value $=$ 72.66, $\mathrm{p}$-value $=0.001$ and degree of freedom $\mathrm{df}=2$. Overall $61.11 \%$ of patients are satisfied and agreed that 
now they know their disease condition better than before post counselling.

Table 1: Total no. of patients who agree that doctor has heard them satisfactorily.

\begin{tabular}{|lllll|}
\hline & \multicolumn{2}{c}{ Before counselling } & \multicolumn{2}{c|}{ After counselling } \\
\hline Satisfied & 56 & $51.85 \%$ & 86 & $79.62 \%$ \\
\hline $\begin{array}{l}\text { Partially } \\
\text { Satisfied }\end{array}$ & 8 & $7.40 \%$ & 20 & $18.51 \%$ \\
\hline $\begin{array}{l}\text { Not } \\
\text { Satisfied }\end{array}$ & 44 & $40.74 \%$ & 2 & $1.85 \%$ \\
\hline
\end{tabular}

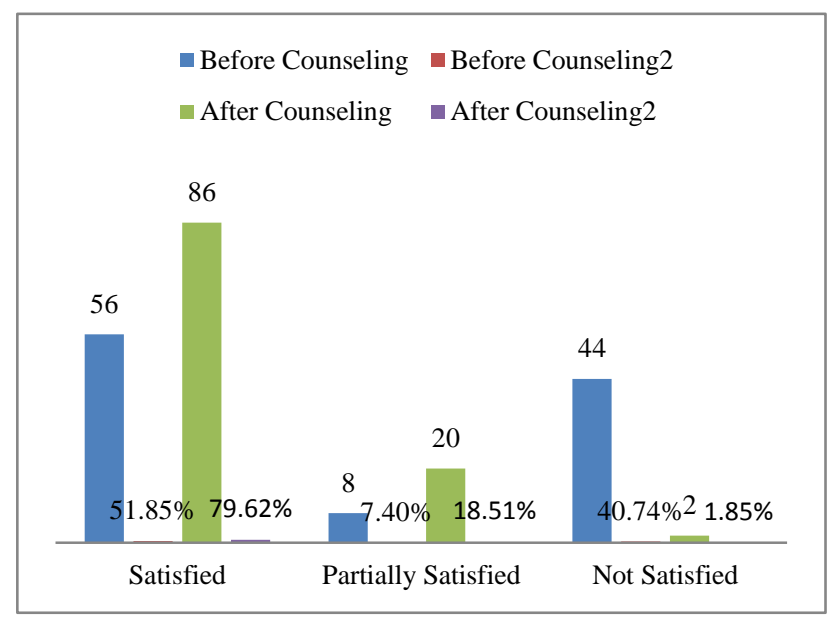

Figure 1: Total no. of patients who agree that doctor has heard them satisfactorily.

Table 2: Percentage of patients satisfied with the examination.

\begin{tabular}{|lllll|}
\hline & \multicolumn{2}{c}{ Before counselling } & \multicolumn{2}{c|}{ After counselling } \\
\hline Satisfied & 44 & $40.74 \%$ & 56 & $51.85 \%$ \\
\hline $\begin{array}{l}\text { Partially } \\
\text { Satisfied }\end{array}$ & 16 & $14.81 \%$ & 17 & $15.74 \%$ \\
\hline $\begin{array}{l}\text { Not } \\
\text { Satisfied }\end{array}$ & 48 & $44.44 \%$ & 35 & $32.407 \%$ \\
\hline
\end{tabular}

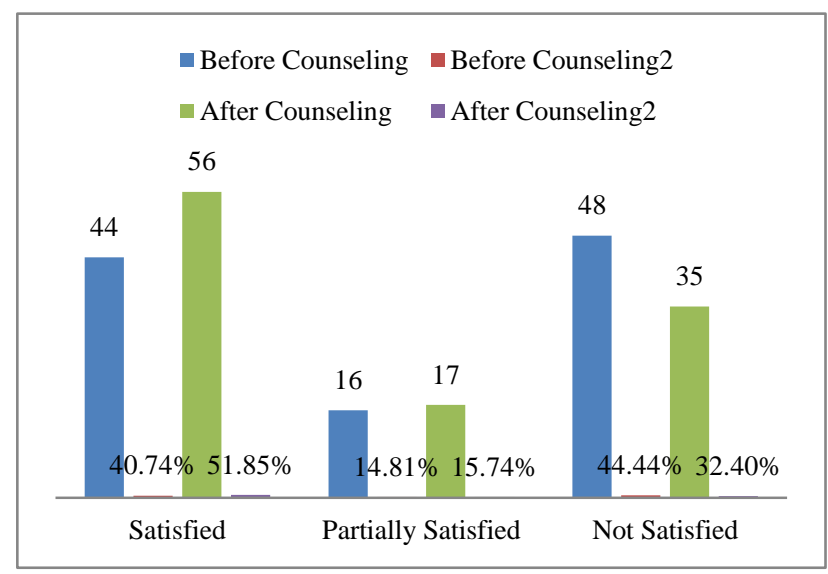

Figure 2: Percentage of patients satisfied with the examination.
Table 3: Percentage of patients who believes that they are satisfactorily explained about their disease.

\begin{tabular}{|llcll|}
\hline & \multicolumn{2}{c}{ Before counselling } & \multicolumn{2}{c|}{ After counselling } \\
\hline Satisfied & 8 & $7.40 \%$ & 66 & $61.11 \%$ \\
\hline $\begin{array}{l}\text { Partially } \\
\text { Satisfied }\end{array}$ & 58 & $53.70 \%$ & 32 & $29.62 \%$ \\
\hline $\begin{array}{l}\text { Not } \\
\text { Satisfied }\end{array}$ & 42 & $38.88 \%$ & 10 & $9.25 \%$ \\
\hline
\end{tabular}

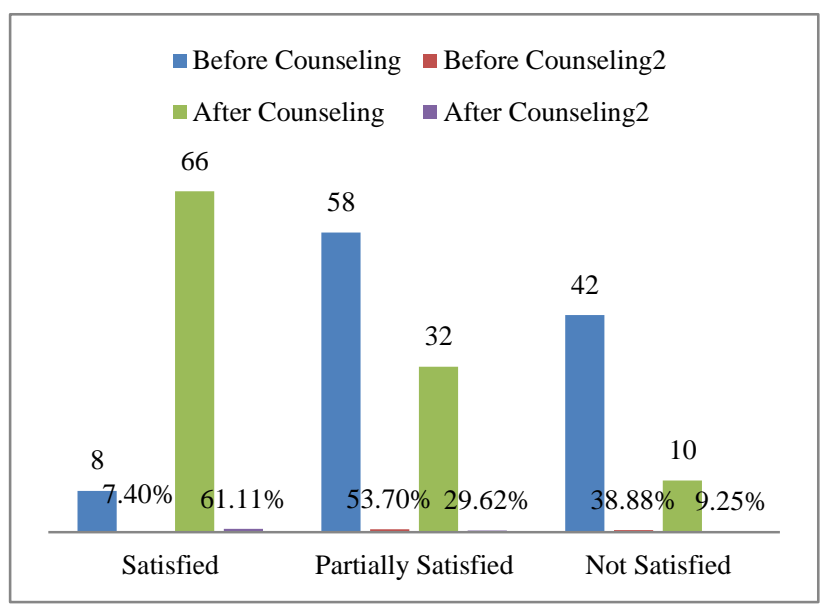

Figure 3: Percentage of patients who believes that they are satisfactorily explained about their disease.

Table 4: Percentage of patients who believes that their diagnosis is rightly made.

\begin{tabular}{|llllc|}
\hline & \multicolumn{2}{c|}{ Before counselling } & \multicolumn{2}{c|}{ After counselling } \\
\hline Satisfied & 56 & $51.85 \%$ & 81 & $75 \%$ \\
\hline $\begin{array}{l}\text { Partially } \\
\text { Satisfied }\end{array}$ & 8 & $7.40 \%$ & 19 & $17.5 \%$ \\
\hline $\begin{array}{l}\text { Not } \\
\text { Satisfied }\end{array}$ & 44 & $40.74 \%$ & 8 & $7.4 \%$ \\
\hline
\end{tabular}

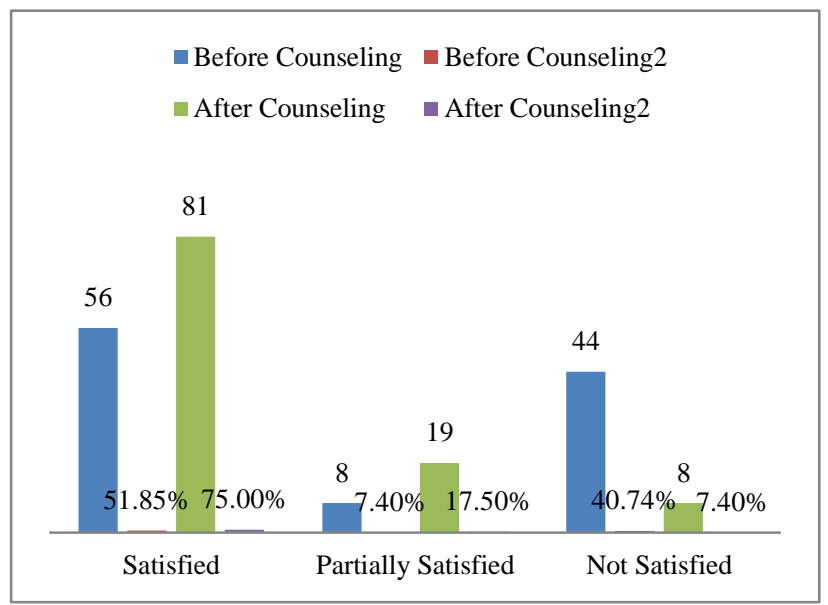

Figure 4: Percentage of patients who believes that their diagnosis is rightly made. 
In Table 4, There was a significant change in the satisfaction level of patients post counselling for right diagnosis made by doctor is found to be statistically significant chi square value $=33.9, \mathrm{p}$-value $=0.001$ and degree of freedom $\mathrm{df}=2$. After counselling satisfied patients has increased from $51.85 \%$ to $75 \%$.

In Table 5, There was a significant change in the satisfaction level of patients post counselling regarding agreed for surgery by patients is found to be statistically significant chi square value $=5.14, p$-value $=6.02$ and degree of freedom df $=1$. Satisfied patients percentage has increased from $21 \%$ to $35 \%$. Other patients want to have second opinion regarding surgery in want that another surgeon may change the decision for surgery and only medicines will cure their problem.

Table 5: Percentage of patients agreed for surgery.

\begin{tabular}{|lllll|}
\hline & \multicolumn{2}{c}{ Before counselling } & \multicolumn{2}{c|}{ After counselling } \\
\hline Satisfied & 23 & $21.25 \%$ & 38 & $35 \%$ \\
\hline $\begin{array}{l}\text { Partially } \\
\text { Satisfied }\end{array}$ & 00 & $0 \%$ & 00 & $0 \%$ \\
\hline $\begin{array}{l}\text { Not } \\
\text { Satisfied }\end{array}$ & 85 & $78.70 \%$ & 70 & $64.81 \%$ \\
\hline
\end{tabular}

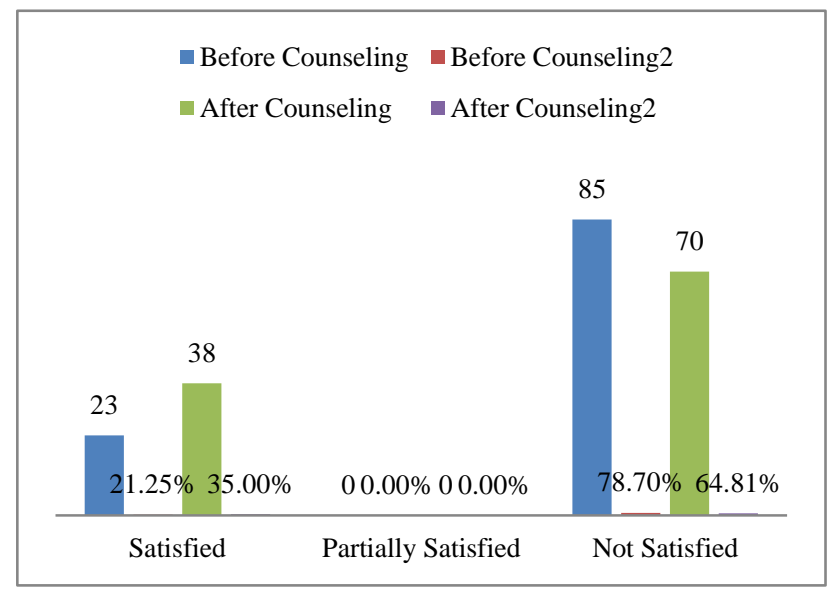

Figure 5: Percentage of patients agreed for surgery.

Average mean time given to the patients in OPD 4-5 minute. Time taken for surgical counselling.

Range $=6-11$ minutes.

Average mean $=(6+11) / 2=8.5$ minutes.

Table 6: Average mean before counselling.

\begin{tabular}{|llll|}
\hline Satisfied & $\mathbf{5 6}+\mathbf{4 4 + 8 + 5 6 + 2 3 / 5}$ & $\mathbf{1 8 7 / 5}$ & $\mathbf{3 7 . 4 \%}$ \\
\hline $\begin{array}{l}\text { Partially } \\
\text { Satisfied }\end{array}$ & $8+16+58+8+0 / 5$ & $90 / 5$ & $18 \%$ \\
\hline $\begin{array}{l}\text { Not } \\
\text { Satisfied }\end{array}$ & $44+48+42+44+85 / 5$ & $263 / 5$ & $52.6 \%$ \\
\hline
\end{tabular}

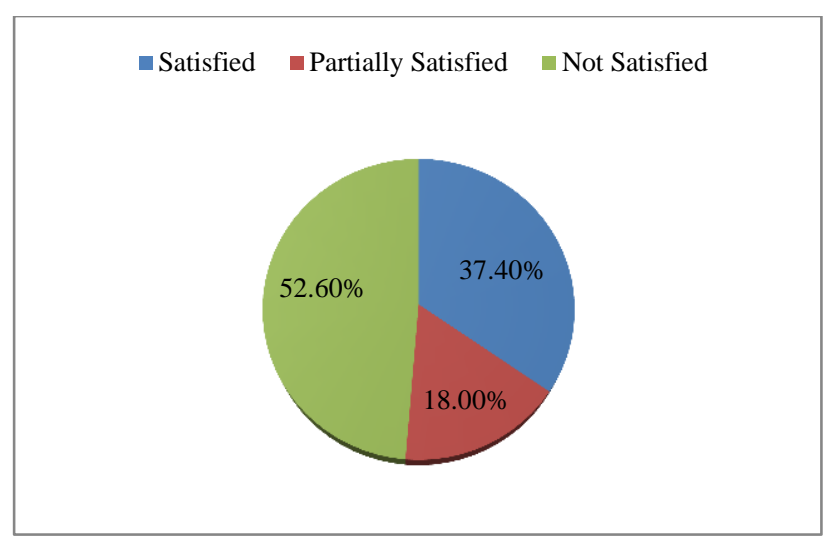

Figure 6: Average mean before counselling.

Table 7: Average mean after counselling.

\begin{tabular}{|llll|}
\hline Satisfied & $\begin{array}{l}\mathbf{8 6 + 4 4 + 8 1 + 6 6 +} \\
38 / 5\end{array}$ & $\mathbf{3 1 5 / 5}$ & $\mathbf{6 3 \%}$ \\
\hline $\begin{array}{l}\text { Partially } \\
\text { Satisfied }\end{array}$ & $\begin{array}{l}20+16+32+19+ \\
\text { Not }\end{array}$ & $87 / 5$ & $17.4 \%$ \\
\hline $\begin{array}{l}\text { Satisfied } \\
2+48+10+8+70 / 5\end{array}$ & $138 / 5$ & $27.6 \%$ \\
\hline
\end{tabular}

\section{$\square$ Satisfied $\quad$ Partially Satisfied $\quad$ Not Satisfied}

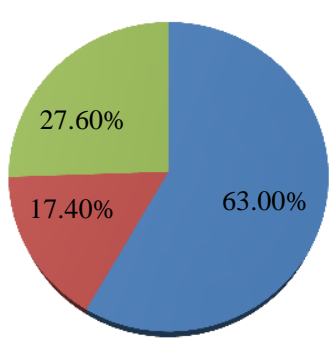

Figure 7: Average mean after counselling.

\section{DISCUSSION}

Satisfaction is a phenomenon of subjective wellbeing. Patient empowerment is a new concept slowly gaining pace in the developing countries. It includes providing the patient with the latest available knowledge about his health status, health problem, diagnosis, prognosis of his ailment, treatment modalities available, probable outcome of each modalities of treatment, benefits versus drawbacks of treatment, everything in patients own understanding language so as to win confidence of patient after satisfying his queries for disease to allow his body to cope stress of the diagnosis and treatment procedure. This improves confidence, satisfaction and finally overall outcome especially in surgical practice. Information from patient satisfaction surveys can be used to assess the quality of the process and outcome of care, and may be used to choose between alternative methods of providing 
health care. ${ }^{8}$ Services that were likely to predict satisfaction were general satisfaction, doctor communication skill, doctor social skills, doctor competence etc. Patients satisfaction questionnaire may be of use by comparing scores before and after the changes. ${ }^{9}$ Grogan and colleagues have shown that, there is no gold standard for patient satisfaction instrument. ${ }^{10}$ One of the major strengths of this questionnaire is that it enables patients to express satisfaction/ dissatisfaction. $^{11,12}$ Patients' views on specific areas enable service providers to distinguish between genuine satisfaction/ dissatisfaction and the general tendency of patients to report that they are satisfied. ${ }^{13,14}$ In our study, A brief, to the point, easily understandable, and easy to be completed by adults more than 18 years questionnaire were prepared based on common problems on doctor patient relationship. Patients were excluded if less than 18 years of age, too ill to complete the form. Questionnaire were not marked in any way that might permit identification of patients and the method of collecting the filled forms was chosen so that patients could feel certain that their comments would be anonymous. The questionnaire was also labelled to indicate that might not implicit as an inquiry about satisfaction from the patient's own doctor which might inhibit the expression of negative opinions. The method of questioning chosen was a five- point Likert-type scale asking for agreement or disagreement with statements about the doctor and the consultation. This scaling method has been employed in other surveys and has the advantage of being relatively easy for respondents to complete. $^{15-17}$ Results obtained in our studies were analysed using SPSS and found to be statistically significant.

In our study total 108 patients coming to surgical OPD were taken out of which $66(61.11 \%)$ were males and 42 $(38.88 \%)$ were females. All of them are above 18 years of age group. The youngest was 18 years and eldest was 66 years of age. Females were found to be more satisfied after patient empowerment and counselling as compared to males. Older patients were found to be more satisfied than younger ones which are comparable with the international studies. ${ }^{18}$ In our study, females took much time for empowerment, understanding and counselling but found to be more firm on the decision once taken by them.

In our study, overall satisfaction level of patients has increased after counselling and patient empowerment (from 37\% - 63\%) table 6 and 7. Consultation time spent with doctor is an important attribute to determine satisfaction level among patients. Studies indicated that longer contact time have been significantly associated with better recognition and handling of physical problems and patient empowerment. ${ }^{19}$ Short contact time with healthcare personnel is a common source of patient dissatisfaction with consultation process. $^{20}$ Our study findings are similar to Ranjeeta et al and Mohd and Chakravarty. Studies who observed consultation time to be (6.6 +/- 3.7 min.) with $85.2 \%$ satisfied with such consultation. $^{20,21}$ In our series $79.62 \%$ patients are satisfied after counselling and empowerment (Table 1). Attributes that hold steady for good doctor patient relationship are sympathy and kindness, good communication between patients and doctors and patience and shared responsibility in managing illness of the patient. Privacy and confidentiality are not only basic rights of the patients but also serve towards a trustful, frank and open relationship with the doctor, thus improving patient care. ${ }^{22}$ In our study satisfaction level was high regarding spending adequate time with the patient, explanation of the disease ,use of easy understanding language during patient empowerment and counselling, regarding explanation about sickness to patients, maintaining respect, privacy and dignity during the consultation process among patients. Average mean time for counselling in our series is 8.5 minutes. On an average more than 8.5 minutes should be given to each patient for obtaining his satisfaction in our series. Counselling time may vary from patient to patient depending on his literacy, background, socioeconomic factors and pre consultations with the doctors of other pathies and quacks. More literate patients have more queries for their disease. Males are easier to satisfy as compared to females but once decided females are more firm for their decision. All the patients were literate (studied more than $12^{\text {th }}$ standard) and above 18 years of age. Patiently patients hearing and cautiously controlled patient empowerment are a must, which satisfies patient most $(79.6 \%)$ after counselling.

\section{CONCLUSION}

It can be concluded from the study that,

(1) There is a definite increase in average satisfaction level of surgical patients after counselling. Approximately $80 \%$ patients are satisfied after counselling and patient empowerment. Overall, Average satisfaction level of surgical patient is $37 \%$ before counselling which raised to $63 \%$ after counselling.

(2) Relationship of literacy and acceptance for surgery: Counselling time may vary from patient to patient depending on his literacy, background, socioeconomic factors and pre consultations with the doctors of other pathies and quacks.

(3) Feedback on our workings: it is seen that we have to change our approach for patients and by simply spending more time and patient empowerment we are able to satisfy our patients more after counselling.

(4) Psychology of surgical patients: It is observed that the general psychology of surgical patients is to take second opinion unless and until told to them during their previous consultations by some other physician for surgery.

(5) Improving ourselves: there is always room for the improvement - it is seen that by bringing very minor changes in our dealing with the patients we are able to convert more no. of routine surgical patients for surgery. 
(6) Average Optimal time for surgical counselling in our study is $8.5 \mathrm{~min}$.

Making of a successful surgeon requires apart from extensive knowledge of his subject, he should be able to know the psyche of patients, hearing them and giving them sufficient time will solve most of problems for flourishing his practice, becoming a good, sensible and famous surgeon and will help to avoid so many unnecessary medico-legal litigations against innocent surgeons.

\section{Funding: No funding sources}

Conflict of interest: None declared

Ethical approval: The study was approved by the institutional ethics committee

\section{REFERENCES}

1. Kincey J, Bradshaw P, Ley P. Patients satisfaction and reported acceptance of advice in general practice. J R Coll Gen Pract. 1975;25:558-66.

2. Donabedian A. Guideposts to a conference on quality assessment and assurance. Shanahan $\mathrm{M}$. Proceedings of an international conference on quality assurance in health care. Chicago: Joint Commission on Accreditation of Hospitals, 1987.

3. Baker R. Development of a questionnaire to assess patient's satisfaction with consultations in general practice. Br J of Gen Prac. 1990;40:487-90.

4. Baker R. The reliability and criterian validity of a measure of patients satisfaction with their general practice. Fam Pract. 1991;8:171-7.

5. (Bollam MJ, Mc Carthy M, Modell M. patients assessment of out of hours care in general practice. Br Med J. 1988;296:829-32.

6. Morrell DC, Evans ME, Morris RW, Roland MO. The 'five minute' consultation: effect of time constraint on clinical content and patients satisfaction Br Med J. 1986;292:870-3.

7. Kaim-Caudle PR, Marsh GN. Patient satisfaction survey in general practice. Br Med J. 1975;1:262-4.

8. Fitzpatrick R. Surveys of patient's satisfaction. I: important general considerations. BMJ. 1991;302:887-9.

9. Grogan S, Conner $\mathrm{M}$ et al. Development of a questionnaire to measure patients satisfaction with general practioners services. B J Gen Pract. 1995;45:525-9.

10. Grogan et al. Quality in health care. 2000;9:199202.

11. Mitchie S, Kidd J. Happy ever after Health Serv J. 1994;3:27.

12. Williams B. Patient satisfaction: a valid concept? SocSci Med. 1994;38:509-16.

13. Hopton J, Howie J, Porter M. The need for another look at patient in general practice patient satisfaction surveys. Fam Pract. 1993;10:82-7.

14. Wensing M, Grol R, Smits A. Quality judgements by patients on general practice care: a literature analysis. SocSci Med. 1994;38:45-53.

15. Likert R. Technique for measure of attitudes. Arch Psycol (New York). 1932;140:44-53.

16. Ware JE, Snyder, MK, Wright R, Davies AR. Defining and measuring patient satisfaction with medical care. Evaluation Programme Planning. 1983;6:247-63.

17. Hulka BS, Zyzanski SJ, Cassell JC, Thompson SJ. Scale for the measurement of attitudes towards physicians and primary medical care. Med Care. 1970;8:429-36.

18. Howie JGR, Porter AMD, Hompton JL. Long to short consultation ratio: a proxy measure of the quality of care for general practice. Br J Gen Pract. 1991;41:48-54.

19. Cape J. Consultation length, patient estimated consultation length and satisfaction with consultation. Br J Gen Pract. 2002;52:1004-6.

20. Ranjeeta K, Idris MJ, Bhushan V, Khanna A, Agrawal M, Singh SK. Study on patient satisfaction in the government Allopathic Heaith Facilities of Lucknow district, India. Indian J Community Med. 2009;34:35-42.

21. Mohd A, Chakravarty A. Patient satisfaction with services of the outpatient department. Med J Armed Forces India. 2014;70(3):237-42.

22. Sankar P, Mora S, Merz JF, Jones NL. Patient perspectives of medical confidentiality: a review of the literature. J Gen Intrn Med. 2003;18:659-69.

Cite this article as: Rakhonde AK, Seth AN, Rakhonde N, Chanchlani R. A prospective study of level of satisfaction among surgical patients in a tertiary care hospital of central India. Int Surg J 2015;2:499-504. 